\title{
Ultrasound imaging of anatomical variations of humeral insertions of the subscapular muscle
}

\author{
Thyl Snoeck, Lucie Selfslagh, Frederic Paillaugue, Steven Provyn
}

\begin{abstract}
Aims: The purpose of this study was to highlight the variations of the humeral insertion of the muscle in vivo, by means of an ultrasound (US) device to depict anatomical variations that could lead to instability of the scapulohumeral complex. Methods: This prospective study (IRB approval) brings a dynamic imaging of the anatomical variation by US exploration of 193 shoulders to confirm MRI and dissection approaches. Results: The results confirm the previous classification of two different classes of organization. 20\% with a non-fibrous bridge over the intertubercular groove (type I and II combined) and $80 \%$ with a fibrous bridge over the tendon of the long head of the bicipital tendon muscle (type III and IV combined). Furthermore, statistical analysis (Fisher and Chi square test with a threshold of 95\%) showed that this variation is not related to gender, side or laterality. Conclusion: This study shows the same results as obtained by dissection or MRI, meaning that this non-radiating, easy
\end{abstract}

Thyl Snoeck ${ }^{1}$, Lucie Selfslagh², Frederic Paillaugue ${ }^{2}$, Steven Provyn $^{3}$

Affiliations: ${ }^{1}$ Department of Anatomy, Morphology and Biomechanics, Professor, Haute école Bruxelles Brabant, Avenue Charles Schaller 91 - 1160 Brussels, Belgium; ' $D$ epartment of Anatomy, Morphology and Biomechanics, Lecturer, Haute école Bruxelles Brabant, Avenue Charles Schaller 91 - 1160 Brussels, Belgium; ${ }^{3}$ Head of Department, Anatomical Research and Clinical Studies, Professor, Vrije Universiteit Brussel, Laarbeeklaan 103 - 1090 Brussels, Belgium.

Corresponding Author: Steven Provyn, Vrije Universiteit Brussel, Anatomical Research and Clinical Studies (ARCS), Laarbeeklaan 103 - 1090 Brussels, Belgium; Email: steven.provyn@vub.be

Received: 16 January 2018

Accepted: 12 February 2018

Published: 16 March 2018 to perform technique can be used as a first approach in a dynamic clinical examination to detect anatomical variations of the subscapular muscle.

Keywords: Anatomical variations, Imaging, Subscapular muscle, Ultrasound

\section{How to cite this article}

Snoeck T, Selfslagh L, Paillaugue F, Provyn S. Ultrasound imaging of anatomical variations of humeral insertions of the subscapular muscle. Edorium J Anat Embryo 2018;5:100024A04TS2018.

Article ID: 100024A04TS2018

$* * * * * * * * *$

doi: 10.5348/100024A04TS2018OA

\section{INTRODUCTION}

Pathologies of the shoulder are very common, warranting an exploration with medical imaging to make an accurate diagnosis to start successful therapy. Meaning that the knowledge of anatomical variations is essential for the surgeon to better understand the pathology, make a correct diagnosis, follow-up of the treatment and may avoid misdiagnosis [1].

Anatomical textbooks often describe the subscapular muscle (SCM) as a muscle that originates from the subscapular fossa and ends in a thick tendon on the upper medial part of the lesser tubercle of the humerus. Furthermore, the tendon passes under the coracoid process, and then runs in front of the scapulohumeral articulation. Fibers of this tendon insert on the upper part of the crista lesser tubercle and attach to the anterior part of the articulation capsule [2-3]. 


\section{EDORIUM Journals}

Edorium J Anat Embryo 2018;5:100024A04TS2018.

www.edoriumjournals.com/ej/ae

The purpose of this study was to highlight the variations of the humeral insertion of the muscle in-vivo in comparison with MRI and dissection, by means of an ultrasound device to depict anatomical variations that could lead to instability of the scapulohumeral complex.

\section{MATERIALS AND METHODS}

In this prospective study, 98 white healthy subjects (45 males and 53 females) with an average age of 23 +/- 2.3 years, participated voluntarily. The participants gave written informed consent after they were provided with expert information in line with the procedures put in place by the Academic Bio-Ethical Committee. None of the subjects presented any contraindications to the examination. Their shoulders were examined bilaterally by two independent experts, resulting in 193 usable US examinations. Experts were looking for the precence of a continuum of the tendon of the SCM bridging the IG (Intertubercular Groove).

To facilitate visualization of the insertion of the SCM tendon, of the IG as a whole and of the LHBM tendon, the subjects had a dynamic US exploration of the anterior part of the shoulder (Mindrayß, Bio-medical electronics co., LTD, Shenzhen, China) with a $10 \mathrm{MHz}$ linear probe. Settings of the US device were parameterized for each subject individually to obtain a clear image.

The probe was placed perpendicularly to the IG which had first been located by means of a palpatory examination. The transversal US images were taken at the most visible point of the humeral insertion of the SCM.

\section{RESULTS}

Statistical analysis was conducted using prism for Windows 5.03 (GraphPad Software, La Jolla, USA). Chi square was used to analyse the differrence between MRI, dissection and US shoulder investigation. Significance was set a priori at $\mathrm{p}<0.05$.

The visual analysis of the US images allowed us to classify the anatomical variations into four categories in line with the classification suggested by Mac Donald in 2007 [6], divided in accordance with the following proportions.

The ultrasound transversal view can be classified into four types (Figures 1-4).

This classification into four types depicts that there are two different organizational classes: (i) without a fibrous bridge (20\%) over the IG (types I and II combined) and (ii) with a fibrous bridge (80\%) over the IG (types III and IV combined).

We wanted to establish how these variations could be divided in function of gender, side examined and of an uni- or bilateral presence. A Fisher's exact test with a 95\% threshold was used. The statistical analysis did not highlight any interi or intra-group statistical significance. In other words, there is no association between the three variables studied. To compare the different examination techniques and their results (dissection, MRI and US), we compared the data from earlier studies $[6,7]$ (Table 1 ).

The Chi square test with a threshold of 95\% was used to compare the different outcomes by author. No significant difference between the techniques could be noted $(p=3.11)$. Our results confirm that the methods used to investigate the anatomical variations of the SCM are consistent with one another.

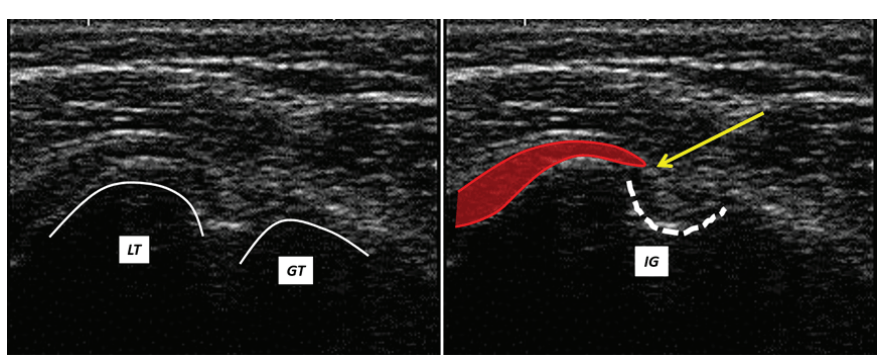

Figure 1: Ultrasound transversal view Type I: The fibers (yellow arrow) of the SCM tendon are exclusively attached to the lesser tubercle; LT = lesser tubercle; GT = greater tubercle; IG = intertubercular groove; LHSM = long head of biceps muscle.

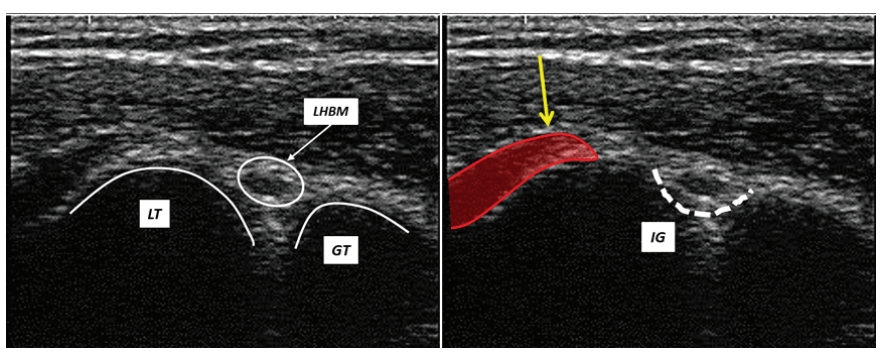

Figure 2: Ultrasound transversal view Type II: The fibers (yellow arrow) of the SCM tendon insert into the IG of the humerus (close to the LHBM tendon); LT = lesser tubercle; GT = greater tubercle; IG = intertubercular groove.

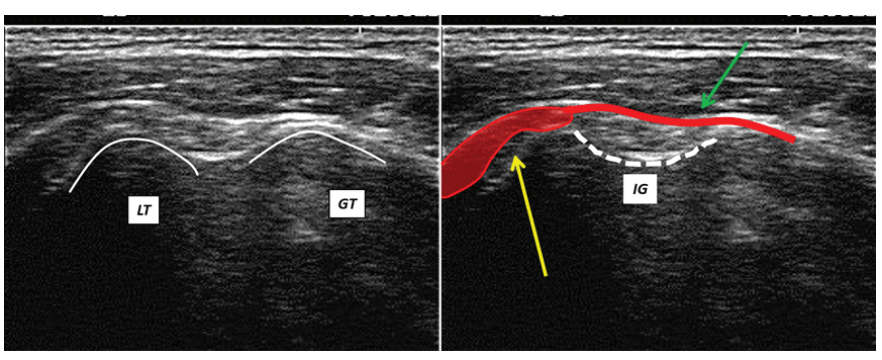

Figure 3: Ultrasound transversal view Type III: The fibers (yellow arrow) of the SCM tendon insert into the IG of the humerus and, by means of aponeurotic fibers (green arrow), extend above the LHBM tendon as far as the greater tubercle; $\mathrm{LT}=$ lesser tubercle; $\mathrm{GT}$ = greater tubercle; $\mathrm{IG}=$ intertubercular groove. 


\section{EDORIUM Journals}
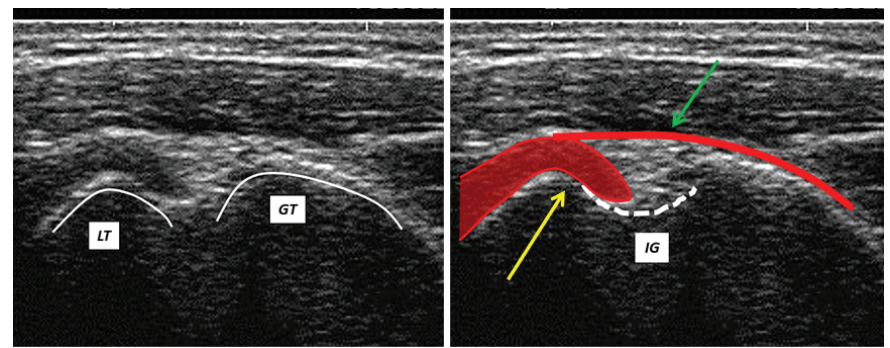

Figure 4: Ultrasound transversal view Type IV: The fibers (yellow arrow) of the SCM tendon are attached to the lesser tubercle by means of aponeurotic fibers (green arrow), extend as far as the greater tubercle, running above the IG; LT = lesser tubercle; GT = greater tubercle; IG = intertubercular groove.

Table 1: Data illustrating the different techniques used to examine the insertion of the subscapular muscle

\begin{tabular}{lccc} 
Type & Dissection & MRI & US \\
\hline & $\begin{array}{c}\text { Mac Donald et al. } \\
\text { 2007 }(\mathrm{n}=85)\end{array}$ & $\begin{array}{c}\text { Cash et al. } \\
2009(\mathrm{n}=58)\end{array}$ & $\begin{array}{c}\text { This Study } \\
(\mathrm{n}=193)\end{array}$ \\
I & $8 \%$ & $20 \%$ & $16,5 \%$ \\
II & $6 \%$ & $66 \%$ & $3,5 \%$ \\
III & $27 \%$ & & $35,5 \%$ \\
IV & $59 \%$ & $14 \%$ & $44,5 \%$
\end{tabular}

Abbreviations: MRI = Magnetic resonance imaging; US = Ultrasound; Type-I, II, III, IV = classification by Mac Donald et al. 2007

\section{DISCUSSION}

According to Beauthier and Lefevre (1991), anatomical variations in humeral insertion are rather rare [4]. The authors describe the most common variation as an independent band of tissue that runs from the medial edge of the scapula to the glenohumeral capsule or the periost inside the intertubercular groove (IG) [5].

In a cadaver study, Mac Donald et al. (2007) noticed that the fibers of the SCM tendon run above the tendon of the long head of biceps muscle (LHBM) in $86 \%$ of the shoulders [6]. These fibrous expansions insert on the greater tubercle of the humerus. In 33\% of dissections, fibers of the SCM tendon glided under the LHBM tendon and inserted into the IG. In $8 \%$ of the cases, the SCM tendon solely attached to the lesser tubercle [6].

In the MRI study of Cash et al. (2009), only $20 \%$ of the observations matched with the description of the 'classic' anatomy textbooks [7]. A dynamic approach using US should allow us to put forward a number of hypotheses linking the presence of these variations to injury processes [8].

This anatomical study, using ultrasound, on 193 shoulders has highlighted the anatomical variations in the humeral insertion of the SCM tendon. Our results agree with those ensuing from earlier studies (cadaver dissection or in-vivo MRI) [4, 7, 9].
Certain authors have shown that SCM tendon ruptures, often remain unnoticed on routine MRI $[6,10]$. Furthermore, it may be advisable to use US to investigate pathologies of the shoulder [11]. As US examinations are dynamic in nature, they also allow for functional tests of the SCM and for the examination of possible anatomical variations and their relationships.

Several authors report the presence of SCM fibers running under the LHBM tendon $[6,12]$. This affects the uppermost fibers of the SCM tendon. They would contribute to the tensioning of the ligamentary structures (coracohumeral and glenohumeral superior), known to be stabilizers [12]. On the contrary, we could consider that an SCM tendon injury could affect the stability of the scapulohumeral articulation. This affirmation will depend on the close functional interdependent relationship between tissue mobility and the capacity to mobilize during a muscular contraction.

The presence of fibers over the LHBM tendon makes us wonder about the functional impact of this situation. As the muscular fibers create a bridge over the IG, might they in fact not play a role in keeping the LHBM tendon in the IG? This idea was already defended by Mac Donald et al. (2007) who suggested that the fibers of the SCM contribute to the stability of the LHBM tendon [6]. Beall et al. compared surgical techniques and their assessment by MRI; the results underline the high degree of significance ( $p<0.0001)$ between an SCM injury and an LHBM tendon injury [10]. This study does not explain the correlation between injuries but emphasizes the complexity of the shoulder joint. This model offers clinicians an additional anamnestic approach that allow them to highlight related injuries.

The study by Khazzam et al. in 2012 questions the functionality of the LHBM tendon on the shoulder joint complex [13]. As the question remains open to debate, it would be difficult to come to an unequivocal conclusion about the functional implication of aponeurotic expansions of the SCM on the LHBM tendon.

Our probabilistic statistical analysis will enhance the descriptive statistics of the earlier studies. The nonsignificant results shows that there are no differences between gender, the left and right-hand side or unibilateral presence of anatomical variations

The results tally with those ensuing from earlier studies performed on cadavers [6] and by means of MRI [7]. They confirm that ultrasonography is a good alternative examination tool for clinicians to screen the SCM tendon pathology and variation. An examination of this type is non-invasive, easy to use, accessible and allows a highly discriminative investigation. Besides a routine examination of the shoulder, US permits to evaluate the latter in a dynamic context to correlate discriptive anatomy and clinical dysfunctions.

The embryological development of the SCM involve different factors such as genetic regulation, differential growth or position shifting, interaction between tissues 


\section{EDORIUM Journals}

and layers, resulting in possible anatomical variations. The development of the insertion of the SCM is also deeply influenced by the morphogenesis of the joint itself. As its tendon derives part from connective tissue from lateral plate mesoderm and part from sclerotome cells lying adjacent to myotomes [14].

\section{CONCLUSION}

The results of this study are in concordance with the results obtained by dissection or MRI, meaning that ultrasound, a non-radiating easy to perform technique, can be used as a first approach in an dynamic clinical examination to detect anatomical variations of the subscapular muscle.

\section{REFERENCES}

1. Kanatli U, Ozturk BY, Bolukbasi S. Anatomical variations of the anterosuperior labrum: Prevalence and association with type II superior labrum anteriorposterior (SLAP) lesions. J Shoulder Elbow Surg 2010 Dec;19(8):1199-203.

2. Quain J. Elements of Anatomy. London: Taylor and Walton; 1876. p. 198-9.

3. Tillaux P. Traité d'Anatomie Topographique Avec Applications à La Chirurgie. [French]. Paris: Asselin et Houzeau; 1887. p. 487-94.

4. Beauthier JP, Lefevre P. Traité D'Anatomie: De la Théorie à la Pratique Palpatoire. [French]. Paris: De Boeck Universté; 1991.

5. Jacobson JA. Shoulder US: Anatomy, technique, and scanning pitfalls. Radiology $2011 \mathrm{Jul} ; 260(1): 6-16$.

6. MacDonald K, Bridger J, Cash C, Parkin I. Transverse humeral ligament: Does it exist? Clin Anat 2007 Aug;20(6):663-7.

7. Cash CJ, MacDonald KJ, Dixon AK, Bearcroft PW, Constant CR. Variations in the MRI appearance of the insertion of the tendon of subscapularis. Clin Anat 2009 May;22(4):489-94.

8. Morag Y, Jamadar DA, Miller B, Dong Q, Jacobson JA. The subscapularis: Anatomy, injury, and imaging. Skeletal Radiol 2011 Mar;40(3):255-69.

9. Kang CH, Kim SS, Kim JH, et al. Supraspinatus tendon tears: Comparison of 3D US and MR arthrography with surgical correlation. Skeletal Radiol 2009 Nov;38(11):1063-9.

10. Beall DP, Williamson EE, Ly JQ, et al. Association of biceps tendon tears with rotator cuff abnormalities: Degree of correlation with tears of the anterior and superior portions of the rotator cuff. AJR Am J Roentgenol 2003 Mar;180(3):633-9.

11. Daenen B, Houben G, Bauduin E, Lu KV, Meulemans JL. Ultrasound of the shoulder. JBR-BTR 2007 SepOct;90(5):325-37.
12. Arai R, Mochizuki T, Yamaguchi K, et al. Functional anatomy of the superior glenohumeral and coracohumeral ligaments and the subscapularis tendon in view of stabilization of the long head of the biceps tendon. J Shoulder Elbow Surg 2010 Jan;19(1):58-64.

13. Khazzam M, George MS, Churchill RS, Kuhn JE. Disorders of the long head of biceps tendon. J Shoulder Elbow Surg 2012 Jan;21(1):136-45.

14. Fealy S, Rodeo SA, Dicarlo EF, O'Brien SJ. The developmental anatomy of the neonatal glenohumeral joint. J Shoulder Elbow Surg 2000 May-Jun;9(3):217-22.

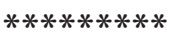

\section{Author Contributions}

Thyl Snoeck - Substantial contributions to conception and design, Acquisition of data, Analysis and interpretation of data, Drafting the article, Revising it critically for important intellectual content, Final approval of the version to be published

Lucie Selfslagh - Substantial contributions to conception and design, Acquisition of data, Analysis and interpretation of data, Drafting the article, Revising it critically for important intellectual content, Final approval of the version to be published

Frederic Paillaugue - Substantial contributions to conception and design, Drafting the article, Revising it critically for important intellectual content, Final approval of the version to be published

Steven Provyn - Substantial contributions to conception and design, Acquisition of data, Analysis and interpretation of data, Drafting the article, Revising it critically for important intellectual content, Final approval of the version to be published

\section{Guarantor of Submission}

The corresponding author is the guarantor of submission.

\section{Source of Support}

None

\section{Conflict of Interest}

Author declares no conflict of interest.

\section{Copyright}

(C) 2018 Thyl Snoeck et al. This article is distributed under the terms of Creative Commons Attribution License which permits unrestricted use, distribution and reproduction in any medium provided the original author(s) and original publisher are properly credited. Please see the copyright policy on the journal website for more information. 


\section{EDORIUM Journals}

Edorium J Anat Embryo 2018;5:100024A04TS2018.

Snoeck et al. 5

Access full text article on other devices

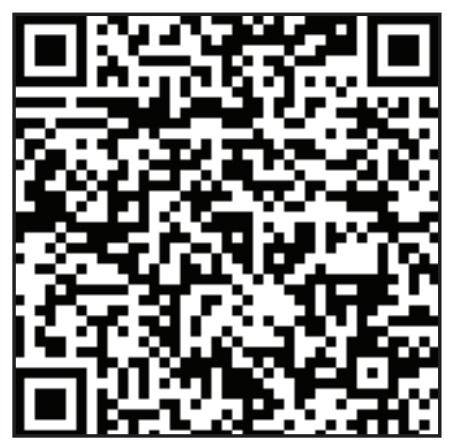

Access PDF of article on other devices

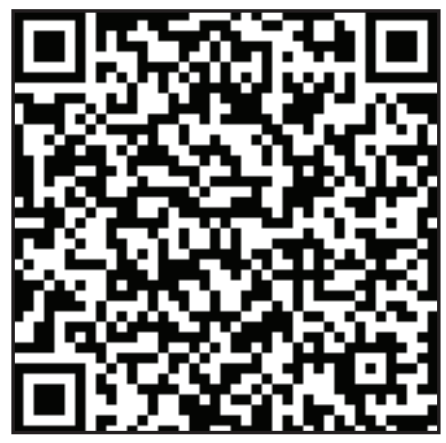

